\title{
Managing Risks Related to ERCP in Elderly Patients with Difficult Bile Duct Stones
}

\author{
Gilmara Coelho Meine • Todd H. Baron
}

Received: 20 July 2014/ Accepted: 24 July 2014/Published online: 9 August 2014

(C) Springer Science+Business Media New York 2014

Endoscopic retrograde cholangiopancreatography (ERCP), since its initial description over four decades ago, has revolutionized the management of biliary disease, with the ability to not only to diagnose biliary stones and strictures, but also to nonsurgically extract stones and dilate and stent obstructions and strictures. Although the development of safer and relatively noninvasive imaging techniques such as magnetic resonance cholangiopancreatography and endoscopic ultrasound has greatly reduced the number of solely diagnostic ERCPs performed, ERCP is still needed for its therapeutic capabilities, in particular ERCP with sphincterotomy (ES), which is generally regarded as safe and effective therapy, with short-term adverse events occurring in 5-10\% of subjects $[1,2]$.

A recent systematic review [3] reported adverse events in older patients undergoing ERCP, concluding that the incidence and risk of developing specific adverse events vary by age. Elderly patients more frequently have morbid underlying diseases, periampullary diverticula, and large multiple common bile duct stones, all of which increase procedure complexity and risk. While most studies describe post-ERCP pancreatitis as the most frequent adverse event after ES, Day et al. [3] report that patients aged $>65$ were $70 \%$ less likely to have an episode of postERCP pancreatitis compared with younger patients. Yet, bleeding and cardiopulmonary events dominated, with a

G. C. Meine ( $\square)$

Department of Digestive Endoscopy, Hospital Regina, Av. Dr. Maurício Cardoso 711, Novo Hamburgo, RS 93510250, Brazil e-mail: gilmeine@terra.com.br

T. H. Baron

Division of Gastroenterology and Hepatology, University of North Carolina School of Medicine, Chapel Hill, NC, USA twofold increase in mortality in octogenarians and nearly a fourfold increase in nonagenarians.

Endoscopic papillary large balloon dilation (EPLBD), first reported by Ersoz et al. [4] in 2003, has become popular for the treatment of difficult bile duct stones, and several studies have reported it is as safe as ES in this setting [5]. Park et al. [6] published a multicenter retrospective study evaluating factors predictive of adverse events following EPLBD, identifying cirrhosis, full-ES, and stone size $\geq 16 \mathrm{~mm}$ as independent predictors for bleeding, while distal common bile duct (CBD) stricture was an independent predictor of perforation. The authors listed some recommendations for a safe EPLBD in patients with difficult bile duct stones, such as: do not perform EPLBD for patients with distal CBD strictures, avoid fullES immediately before large balloon dilation, avoid inflating the dilating balloon beyond the maximal size of the upstream dilated CBD, and discontinue balloon inflation when resistance is encountered in the presence of a persistent balloon waist. Nonetheless, none of the previous studies focused on elderly populations.

In this issue of Digestive Diseases and Sciences, Tonozuka et al. [7] report the efficacy and safety of EPLBD for large bile duct stones in elderly patients. The study included 165 patients (105 patients $\geq 75$ years and 60 patients $<75$ years) with large or multiple common bile duct stones (mean number of stones was $2.9 \pm 2.5$, and the mean maximum stone diameter was $15.9 \pm 5.4 \mathrm{~mm}$ ). Dilation was performed using balloons with maximum diameter varying from 15 to $20 \mathrm{~mm}$. There were no significant differences in initial and final stone clearance rates, adverse event rates, and stone recurrence rates between patients 75 years or older and younger patients. Adverse events included mild hemorrhage ( 1 vs. $3.3 \%$ ), moderate grade post-ERCP pancreatitis (1 vs. $1.7 \%$ ), and perforation (1 vs. 
$0 \%$ ). The one patient who suffered a perforation was treated conservatively with full recovery. There were no cardiopulmonary events or deaths.

According to this retrospective study, EPLBD is at least as safe as ES in the elderly. The lower bleeding rate in elderly patients compared with that reported by Day et al. [3] may be related to the reduced ES size and the more homogeneous comparative groups in this study (both groups had similar stone characteristics). The absence of cardiopulmonary events may be explained by the lower need for mechanical lithotripsy [8, 9] and the reduced mean procedure time [10] required for EPLBD. For example, Fisher et al. [11] reported increased cardiopulmonary complications in elderly patients when ERCP is prolonged for more than $30 \mathrm{~min}$. Nevertheless, large prospective controlled randomized trials would be necessary to confirm these hypotheses.

In conclusion, as the number of elderly patients requiring ERCP increases, its imperative measures are taken to maximize safety, especially in this vulnerable complication-prone population. Papillary dilation with large-diameter balloons in combination with a small sphincterotomy is safe and effective for the removal of large common bile ducts stones [5], and the current study suggests this technique may be safely performed in elderly patients.

\section{References}

1. Vandervoort J, Soetikno RM, Tham TC, et al. Risk factors for complications after performance of ERCP. Gastrointest Endosc. 2002;56:652-656.
2. Masci E, Toti G, Mariani A, et al. Complications of diagnostic and therapeutic ERCP: a prospective multicenter study. Am J Gastroenterol. 2001;96:417-423.

3. Day LW, Lin L, Somsouk M. Adverse events in older patients undergoing ERCP: a systematic review. Endosc Int Open. 2014;02:E28-E36.

4. Ersoz G, Tekesin O, Ozutemiz AO, et al. Biliary sphincterotomy plus dilation with a large balloon for bile duct stones that are difficult to extract. Gastrointest Endosc. 2003;57:156-159.

5. Meine GC, Baron TH. Endoscopic papillary large-balloon dilation combined with endoscopic sphincterotomy for the removal of bile duct stones. Gastrointest Endosc. 2011;74:1119-1126.

6. Park SJ, Kim JH, Hwang JC, et al. Factors predictive of adverse events following endoscopic papillary large balloon dilation: results from a multicenter series. Dig Dis Sci. 2013;58:1100-1109.

7. Tonozuka R, Itoi T, Sofuni A, Itokawa F, Kurihara T, Tsuchiya T, Ishii $\mathrm{K}$, Tsuji S, Ikeuchi N, Umeda J, Tanaka R, Honjyo M, Mukai S, Fujita M, Moriyasu F. Efficacy and safety of endoscopic papillary large balloon dilation for large bile duct stones in elderly patients. Dig Dis Sci. 2014. doi:10.1007/s10620-0143156-9.

8. Kim TH, Oh HJ, Lee JY, et al. Can a small endoscopic sphincterotomy plus a large-balloon dilation reduce the use of mechanical lithotripsy in patients with large bile duct stones. Surg Endosc. 2011;25:3330-3337.

9. Teoh AY, Cheung FK, Hu B, et al. Randomized trial of endoscopic sphincterotomy with balloon dilation versus endoscopic sphincterotomy alone for removal of bile duct stones. Gastroenterology. 2013;144:341-345.

10. Itoi T, Itokawa F, Sofuni A, et al. Endoscopic sphincterotomy combined with large balloon dilation can reduce the procedure time and fluoroscopy time for removal of large bile duct stones. Am J Gastroenterol. 2009;104:560-565.

11. Fischer L, Fischer A, Thompson A. Cardiopulmonary complications of ERCP in older patients. Gastrointest Endosc. 2006;63:948-955. 